\title{
Power flow control with bidirectional dual active bridge battery charger in low-voltage microgrids
}

\author{
Luis M. Miranda, Diogo Varajão, Bruno dos Santos, Rui E. Araújo, \\ C. L. Moreira and J. A. Peças Lopes \\ INESC Porto, Faculdade de Engenharia da Universidade do Porto \\ Campus da FEUP, Rua Dr. Roberto Frias, 378, 4200-465 Porto, PORTUGAL \\ Email: luis.m.miranda@inescporto.pt, diogo.varajao@fe.up.pt, \\ bruno.laranjo@fe.up.pt,raraujo@fe.up.pt, carlos.moreira@inescporto.pt, jpl@fe.up.pt \\ URL: http://www2.inescporto.pt/use-en
}

\section{Acknowledgments}

This work is supported in part by the ERDF - European Regional Development Fund through the COMPETE Program (operational program for competitiveness) and by National Funds through the FCT-Fundação para a Ciência e a Tecnologia (Portuguese Foundation for Science and Technology) within project Microgrids+EV: Identification of Control and Management Strategies for Microgrids with Plugged-in Electric Vehicles, PTDC/EEA-EEL/103546/2008-(FCOMP-01-0124-FEDER-009866).

\section{Keywords}

Microgrid, Power converters for EV, Battery charger, Power quality

\begin{abstract}
This paper describes a power conversion system that implements bidirectional power flow between the electric grid and a battery, based on a full bridge inverter associated with a dual active bridge. A method for power flow control based on the agreement between battery pack and low voltage grid requirements has been developed to allow the large penetration of both, electric vehicles (EV) and renewable microgeneration. A laboratory prototype containing all functions required to implement a vehicle-to-grid (V2G) power interface has been built. The hardware implementation is reported, including control scheme and high-frequency transformer design details. Converter key waveforms are presented to evaluate the power quality on batteries and grid, as well as its dynamic behavior. An experimental laboratory setup is described and results are shown to demonstrate the technical benefits for low-voltage (LV) microgrids, if electric vehicle charger includes a power flow control based on frequency-voltage droop concept.
\end{abstract}

\section{Introduction and motivation}

The recent political debate about energy and climate change is again causing a rise in demand of Electric Vehicles (EVs) [1]. Obviously, using electricity as the energy carrier provides a multitude of options for the primary source of energy, including wind and solar power. However, the future massive integration of EVs into the electric grids represents an important issue to electric power system [2]. Indeed, electric grids were not originally conceived to handle such type of loads. Thus, many authors argue that the demand induced by the EVs is expected to impact the electric power system at both system and local level [3]. With the advent of smart grid technologies implementation, the perspective of using the load as a resource [4] is becoming increasingly attractive because it can reduce and/or postpone the need for additional generation and grid reinforcements . At the same time, recent advancements in the performance of Li-ion batteries connected through bidirectional interfaces based on power electronics are an attractive type of flexible device to provide both energy and power intensive grid support services [5]. In this context, the advanced EV charger with V2G functionality addressed in this work is key technology to enable the future implementation of the so-called smart charging of electric vehicles [6].

Several bidirectional charging topologies for EVs were proposed and analyzed in [7-9]. This work presents an isolated bidirectional converter with the power flow control capability for low-power onboard battery charger application. The charger has two stages: first, a grid tied Full-Bridge (FB) inverter 
that enforces power factor and power control, and an isolated bidirectional Dual Active Bridge (DAB) to regulate battery current. The DAB converter was first introduced in [10] and has been carefully investigated due to its excellent characteristics such as galvanic isolation, bidirectional power transfer, high power density, high efficiency, possibility to achieve zero voltage switching in a wide range of load variation $[11,12]$.

The main originality of this work, from the experimental point of view, is the use of a FB+DAB topology allowing the application of bidirectional power flow, in order to provide advanced grid support functionalities. A prototype of a battery charger was developed to experimentally validate the proposed solution. Details about the high-frequency (HF) transformer design are also shown. Some experiments were carried out in laboratory environment to demonstrate the effectiveness of its architecture and control strategies.

\section{Operation principle of the proposed converter}

Fig.1 presents a block diagram with an architecture overview of the bidirectional battery charger. The power converter hardware can be split into two stages with independent control schemes, making a completely modular system. The first stage is a grid tied full-bridge inverter that controls the power flow between the DC bus and the LV grid. The other stage is a dual active bridge that regulates the current in the batteries and assures galvanic isolation between the grid and the battery pack. Next, the power flow control principle will be presented, as well as the control strategies for microgrids using the bidirectional battery charger.

\section{Power flow control}

The full-bridge inverter control scheme measures the grid voltage and current variables $\left(V_{a c}\right.$ and $\left.I_{s}\right)$ as well as the DC bus voltage $V_{D C 1}$. First, a PLL algorithm $[13,14]$ using grid voltage and current estimates the frequency and phase of the grid voltage, allowing the design of a real time synchronous current control scheme.

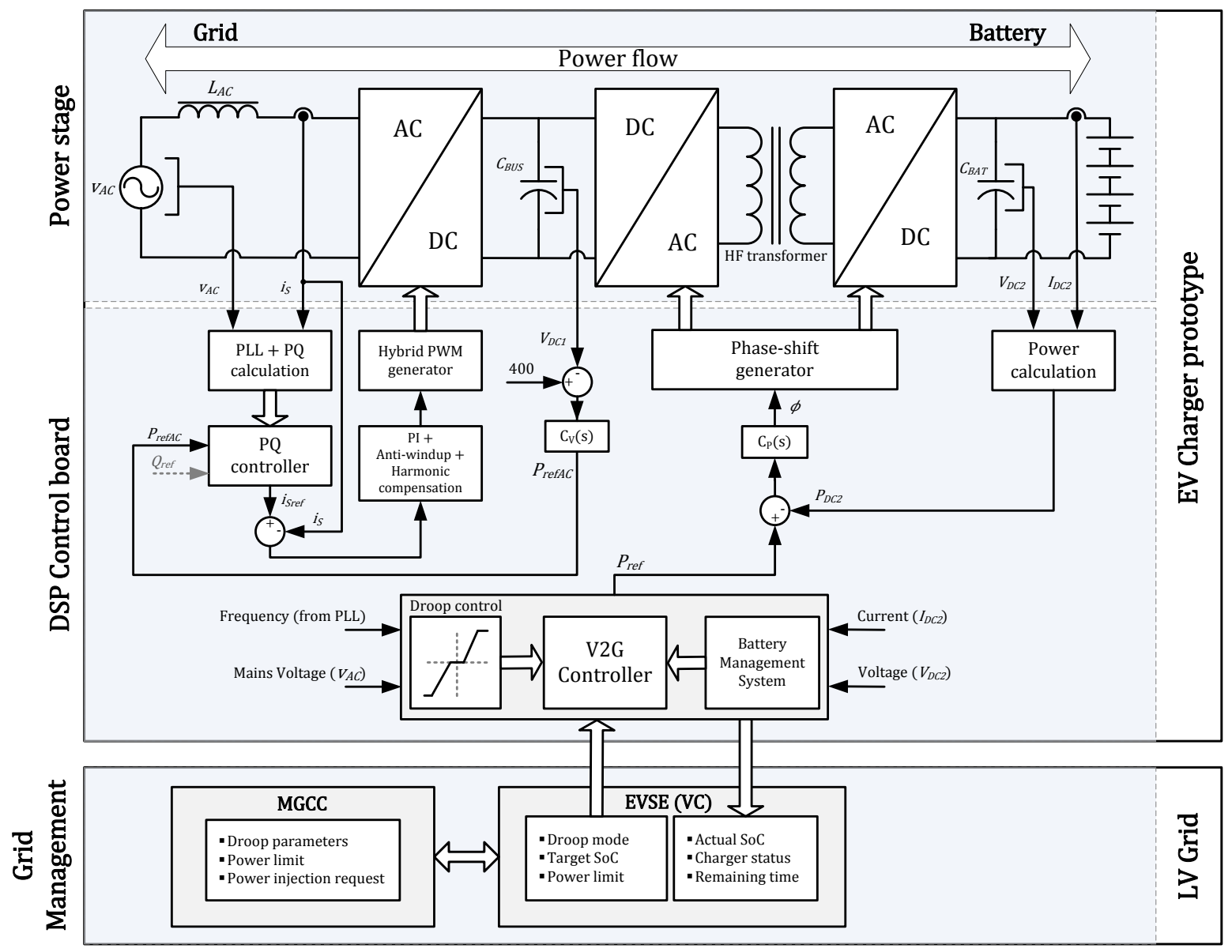

Figure 1: Proposed architecture for the bidirectional battery charger. 
These variables are used to compute active and reactive power that will be used to implement a PQ control. Error compensation is performed by a proportional-integral controller with anti-windup and harmonic compensation features to assure high power quality. Thus the power circuit is switched to adjust the power according to a given reference $(\mathrm{P}, \mathrm{Q})$. The set-point of active power is given by a voltage controller which is in charge of regulating the DC bus voltage $\left(V_{D C 1}\right)$ to $400 \mathrm{~V}$, in order to ensure adequate supply to the DAB input stage. The chosen switching technique was a hybrid modulation, which reduces switching losses by approximately one half when compared to a bipolar switching [15].

The DAB consists of two full bridges connected by means of a high-frequency transformer. This DC-DC converter is controlled in terms of the active power flowing to the battery pack by the phase-shift between the square voltages of both bridges. The battery pack power is calculated measuring the battery voltage and current $\left(V_{D C 2}\right.$ and $\left.I_{D C 2}\right)$ and an error output is used to implement a closed loop control algorithm. In order to control the power flow, the amount of phase shift between voltages of both bridges is controlled in a -90 and +90 range, being the one in advance which delivers power. The expression that shows this control action is:

$$
P_{O}=\frac{V_{D C 1}}{\omega L} \frac{V_{D C 2}}{N} \phi\left(\frac{1-|\phi|}{\pi}\right)
$$

where $V_{D C 1}$ is the input dc voltage, $V_{D C 2}$ is the output dc voltage, $\omega$ is the switching frequency in radians per second, $L$ is the primary-referred leakage inductance, $N$ is the transformer turns ratio, and $\phi$ is the phase-shift between square voltages of the input and output bridges [10]. More details about the power flow control can be obtained from a previous work [9]. The generation of a power reference to this control loop is explained in the next section.

\section{Control strategies for the microgrids}

The large integration of EVs into the electric grids will provoke considerable impact in electric power system operation as a result of significant power consumption during battery charging. In order to successfully integrate electric vehicles into electric power systems, the conceptual framework proposed in [3] can be explored. Given the large grid connection periods for EV charging purposes, it is possible to envision advanced charging strategies, provided that EV battery charger offers the adequate flexibility. In this sense, EV connected to the LV network, which can be regarded as flexible loads or storage devices when controlled through smart charging strategies. However, the contribution of EV will depend on the number of EV connected to the system and on its storage capacity, as well as on the state of charge of its batteries. At the EV charger level, this integration can be achieved through the continuous adjustment of the charging rate as a function of the local grid conditions [16].

At distribution level, due to the lower $X / R$ cable factor, voltage drop can be significant, especially at peak hours, where several others vehicles will also be charging. In order to minimize this impact, a voltage droop can be used to set the power reference and slow down the charging rate [3]. With the large integration of solar and wind microgeneration systems at the distribution level, the grid voltage can be significantly higher than nominal value. In this situation, the charging rate of batteries can even be increased to its maximum power $\left(P_{\max }\right)$ preventing node overvoltages. On the other hand, in case of feeder overloading causing voltage to drop outside the dead-band, the EV can decrease its charging power or even inject power in order to increase the node voltage. This strategy can be implemented through a voltage droop with a characteristic as represented in Fig. 2.

The microgrid (MG) primary control is usually implemented locally as external control loops of the storage unit coupling capable of providing fast power balance (ie. flywheels, ultracapacitors, etc.). In order to provide frequency regulation, the Voltage Source Inverter (VSI) coupled to the energy storage device can be controlled through droop functions, in order to react autonomously to grid operating conditions. During autonomous operation, MG frequency is an instantaneous indication of the power balance in the electric grid. In this sense, EV active power control can be used to improve the MG primary frequency regulation. When connected to the system, the EV can be regarded as flexible loads or even as distributed storage units. Similarly to the voltage droop characteristic in Fig. 2, the EV charging rate will be controlled through an Active Power-Frequency droop characteristic, contributing to ensure power balance within the islanded MG. When the MG load exceeds local generation the MG frequency will drop and the EV will reduce its charging rate or even activate the $\mathrm{V} 2 \mathrm{G}$ mode, providing active power to the grid. Contrarily, if there is an excess of generation regarding the load, the MG frequency will increase and the EV will increase its power consumption. In islanded mode of operation, this strategy can also maximize the integration of renewable energy resources through the EVs participation in the primary frequency control [17].

Therefore, combining grid voltage and frequency values $\left(V_{a c}\right.$ and $\left.f\right)$ it is possible to adapt the charger operation to the local grid conditions and improve power quality, integration of electric vehicles and renewable energy sources in electric power systems $[3,17]$. The voltage and frequency droop characteristics are identical and fully configurable. A dead band is defined by $V_{d b L O / H I}$ and $f_{d b L O / H I}$ around the voltage/frequency nominal value $\left(V_{n} / f_{n}\right)$, where the power set-point $\left(P_{s p}\right)$ remains unchanged. The 

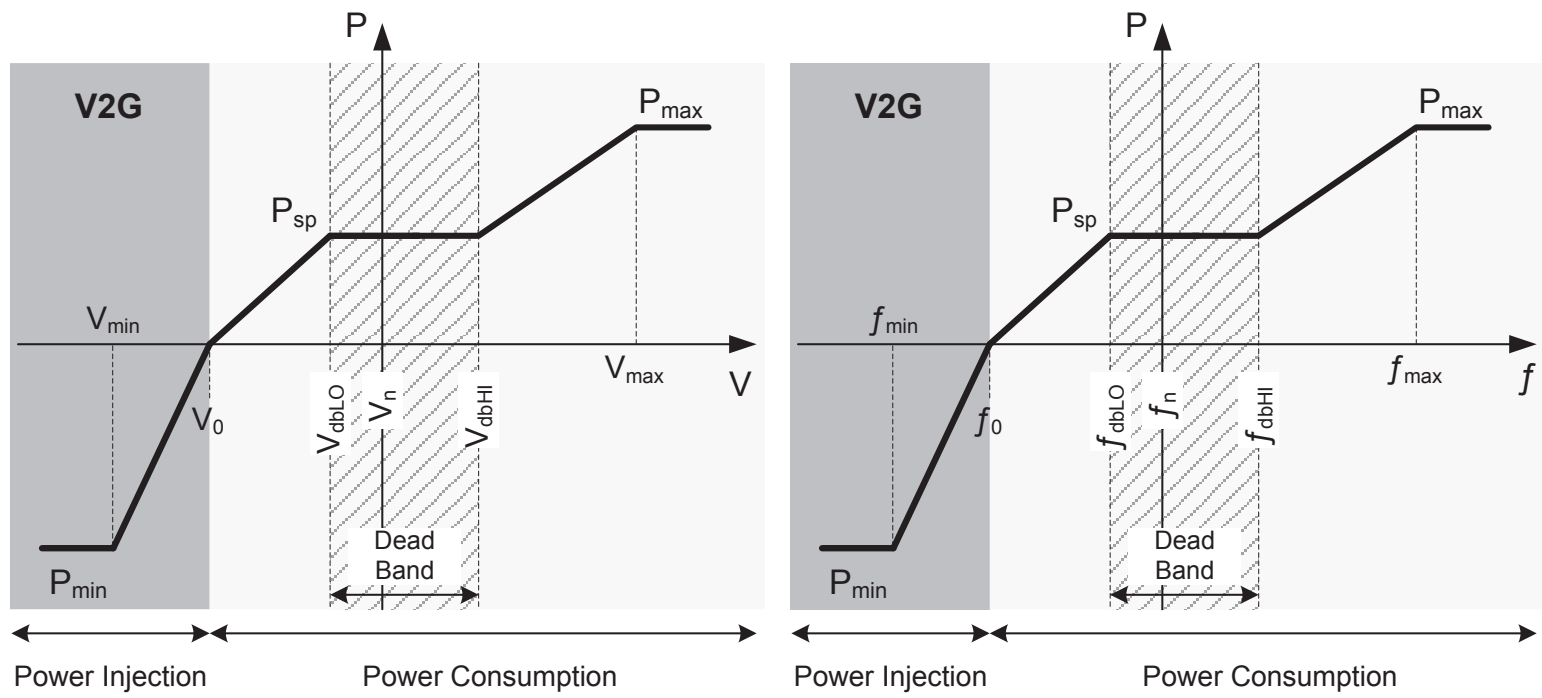

Figure 2: Voltage and frequency droop characteristics.

power can be increased or decreased until it reaches the defined power limits $P_{\max }$ and $P_{\min }$. Under the V2G concept, the $P_{\min }$ value could be negative and so, the zero-crossing voltage/frequency $\left(V_{0} / f_{0}\right)$ is different from $V_{\min } / f_{\min }$. In this situation, the power flow is reversed to provide advanced grid support functionalities [18].

The active power flow between the DC-DC converter and the batteries is defined based on the Battery Management System (BMS) and the voltage/frequency droop characteristic, which can set the power setpoint $\left(P_{s p}\right)$ within a limit of $\pm 3680 \mathrm{~W}$. In normal grid operating conditions, the BMS algorithm charges the batteries based on constant current-constant voltage (CC-CV) method. However, during grid disturbances the voltage/frequency droop characteristics will determine a new reference power in order to adapt battery charging to the local grid conditions. The charging rate defined by the droop control may become limited by the BMS, in order to ensure safe operation conditions of the battery pack [19].

From the grid management side, some interaction with the EV charger prototype is allowed and is essential to implement these control strategies to the microgrids. The MicroGrid Central Controller (MGCC) communicates with the Electric Vehicle Supply Equipment (EVSE) via Ethernet, which communicates with the EV charger by a serial port. Taking into account that low-voltage electrical grid conditions can vary through time, an online droop reconfiguration can be remotely done by the MGCC, which can also limit the charging power or even require V2G operation. At the EVSE unit, the EV owner can configure the charging process.

\section{Prototype description}

With the aim of evaluating the feasibility of the proposed power converter, an experimental setup was constructed. The prototype developed should meet certain requirements defined for this application. It should implement galvanic isolation between the mains supply and the battery pack, and provide precise control of the battery charging current with low ripple. At the grid interface, high power quality must be ensured with low ripple and harmonic content. Lastly, the converter must be able to track current and power set-points with closed loop regulation. These set-points should fall within a range previously specified, being $\pm 3680 \mathrm{~W}$ for the active power transferred and $\pm 9 \mathrm{~A}$ for the charging current.

The power circuit was built to ensure a transfer of nominal power in both directions, within the entire voltage range of the battery pack $(360 \mathrm{~V}$ to $490 \mathrm{~V})$. A tridimensional plot of power as function of battery pack voltage and phase-shift is presented in Fig. 3. For higher levels of voltage, a high phase-shift value will result in excessive power transfer. In these cases, power is limited by the controller for the nominal value. A surface for the load current of the battery is shown in Fig. 4. As it can be seen in the figure, the value is limited to 9A for lower voltage levels and consequently reduced as voltage rises to meet the power limitation. These functions characterize the steady-state operation of the battery charger and were used as a specification for the prototype design. 


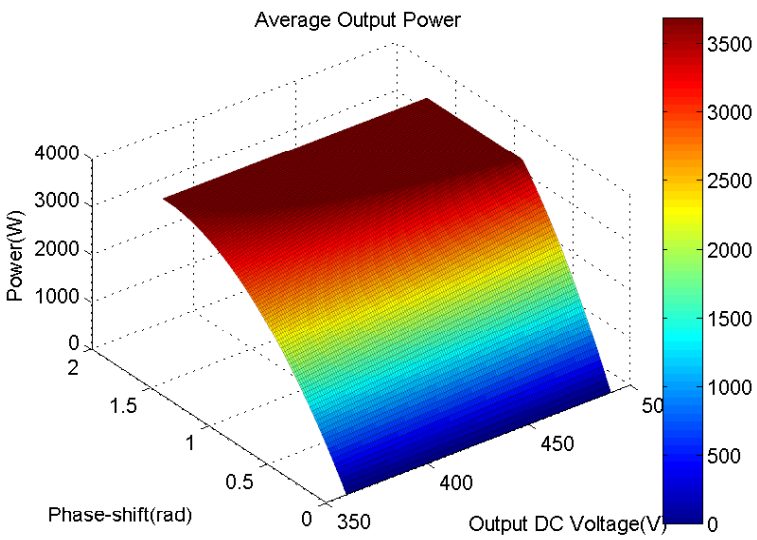

Figure 3: Output power vs. phase-shift and output voltage.

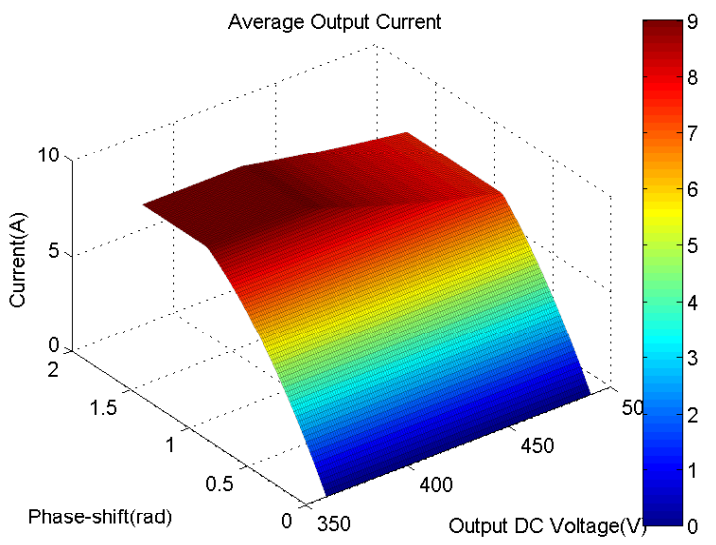

Figure 4: Output current vs. phase-shift and output voltage.

\section{Power stack}

The main prototype parameters are listed in Table I. The grid tied inverter was built in a three-layer architecture. At the bottom, a PCB with auxiliary supply, isolated voltage and current transducers for AC and DC sides, DC Bus capacitor bank, and full bridge IGBT module were assembled. For the middle layer, high performance IGBT drivers (SKHI 24 R from Semikron ${ }^{\circledR}$ ) were mounted to ensure proper and safe operation of the switching devices. On the top of the stack, a TMS320F28335 eZdsp control card is attached to a custom-made printed circuit board with signal conditioning circuitry for both digital and analogue signals. In DAB implementation the selected components are quite similar, which include two full bridges and the capacitor bank sets. Voltage and current transducers are assembled for each DC bus and the HF power transformer is externally mounted.

Table I: Main prototype parameters

\begin{tabular}{|l|l|l|l|}
\hline \multicolumn{2}{|c|}{ Grid inverter } & \multicolumn{2}{c|}{ Dual Active Bridge } \\
\hline DC Bus capacitor bank & $2 \times 1095 \mu \mathrm{F} / 500 \mathrm{~V}$ & Output Filter Capacitor & $1095 \mu \mathrm{F} / 500 \mathrm{~V}$ \\
\hline Line filter & $3 \mathrm{mH}$ & Switching Devices & $2 \times \mathrm{SK} 25 \mathrm{GH} 063$ \\
\hline Switching Devices & SK $25 \mathrm{GH} 063$ & Resonant Capacitor & MKP 1 nF/1000 V \\
\hline Switching Frequency & $30 \mathrm{kHz}$ & Battery Pack & LiFePO4, 410 V/40 Ah \\
\hline
\end{tabular}

\section{HF Transformer design}

The high-frequency transformer is a key component in the design of any isolated electronic power converter. For an on-board charger, which is intended to be highly compact, it is important to design a component with low weight and volume, but without harming significantly the overall converter efficiency.

The design procedure used is adapted from [20], which is based on optimal peak flux density calculation to achieve minimum power losses. The first modification is the assumption that core and wire are previously selected. In most cores, winding area is limited and appears as a design constraint, since it is supposed to be completely filled with copper. In this case the formula was adapted, since a toroid core does not have a very strict winding area, and is not intended to be filled with copper. Instead, it is intended to use the least possible wire layers to allow better core heat dissipation. Table II presents the minimum requirements that the transformer should fulfill. The maximum voltage that should be considered for the battery pack is $490 \mathrm{~V}$ and maximum power losses value was set to $2 \%$ of the rated converter power.

In addition to the requirements imposed by the converter, it was also necessary to make some calculations to get all the data needed to design the transformer. The quantities that have been defined as being variable during the operation of the converter are the battery pack voltage and the phase-shift between the two full bridges, which is used as control variable. Having defined a range for these two variables, an expression was determined for the RMS current as a function of battery pack voltage and phase-shift (Equation 2). A surface was computed to find the higher value of the RMS current (Fig. 5), being this value used as input parameter in the design. Volt-time product was also set to be the highest value, 
considering the converter operating range, i.e., when the battery pack voltage is at its highest value. The time is fixed and equal to half of the switching period.

Table II: Transformer design input data

\begin{tabular}{|l|l|l|l|}
\hline Transformation ratio & $1: 1$ & Phase-shift & $-\frac{\pi}{2} \ldots+\frac{\pi}{2}$ \\
\hline Battery voltage range & $360 \ldots 490 \mathrm{~V}$ & Frequency & $30 \mathrm{kHz}$ \\
\hline Power losses & $<72 \mathrm{~W}$ & Maximum leakage inductance & $325 \mu \mathrm{H}$ \\
\hline Volt-time product & $8167 \mathrm{~V} \mu \mathrm{sec}$ & Maximum RMS current & $18.73 \mathrm{~A}$ \\
\hline
\end{tabular}

$$
I_{R M S}=\sqrt{\frac{\left(V_{D C_{1}}-V_{D C_{2}}\right)^{2}}{6 L_{\sigma}^{2} f_{s}^{2}}+\frac{\phi^{2}\left(V_{D C_{1}}^{2}+V_{D C_{2}}^{2}\right)}{3 L_{\sigma}^{2} \pi^{2} f_{s}^{2}}+\frac{\phi^{2}\left(V_{D C_{1}}-V_{D C_{2}}\right)^{2}}{3 L_{\sigma}^{2} \pi f_{s}^{2}}}
$$

$V_{D C_{1}}$ Input DC voltage of DAB converter (400V, fixed)

$V_{D C_{2}}$ Output DC voltage of DAB converter (Battery pack voltage)

$L_{\sigma} \quad$ Transformer equivalent leakage inductance

$\phi \quad$ Phase-shift between input and output bridge

$f_{s} \quad$ Switching frequency

For the transformer core, ferrite was the selected material because of its low cost and high commercial availability. Whereas it is a prototype version of the component and the windings were handmade with a low copper fill factor, the toroid shape seemed to be quite interesting. In the first iteration of calculations it was found that copper losses were very high compared to core loss. In order to avoid using a very large wire, the solution adopted has to use two identical pieces of ferrite in parallel to increase the effective core cross-section. Considering the skin depth effect and the switching frequency, it was found that the maximum wire gauge that should be used is AWG21. The design procedure was repeated, increasing the number of parallel wires to find a trade-off between copper losses and the difficulty of construction. A reasonable balance was found using five parallel wires, with total losses down to $1.14 \%$ of the rated converter power. The value of the peak flux density corresponding to this case is also far from the material limits of the $3 \mathrm{C} 90$ ferrite, which is $380 \mathrm{mT}$ for $100^{\circ} \mathrm{C}$, keeping the transformer operation away from core saturation. An output of the computer script developed to perform the calculations is presented in Fig. 6 .

Another critical issue is related to the magnetization inductance that should be high enough so that the magnetizing current can have a low value. In this case, since the magnetic circuit has a high cross section, the inductance factor value is high as well. A peak-to-peak current of about $0.7 \mathrm{~A}$ is expected when a square wave of $490 \mathrm{~V}$ is applied to the transformer winding. The leakage inductance was not estimated during the design, although there was an effort to minimize it. The primary and the secondary turns are interleaved so that both windings can have identical geometry. Being this value of great importance for the DAB operation, it had to be measured during an experiment with the secondary in short circuit. It was found that the value is below the upper limit, necessary to ensure the required power transfer at any given point of operation. Moreover, it appears that the value is too low, which makes it necessary to put additional inductance in series to limit the current slopes in transformer windings. A summary of the main parameters resulting from transformer design is presented in Table III.

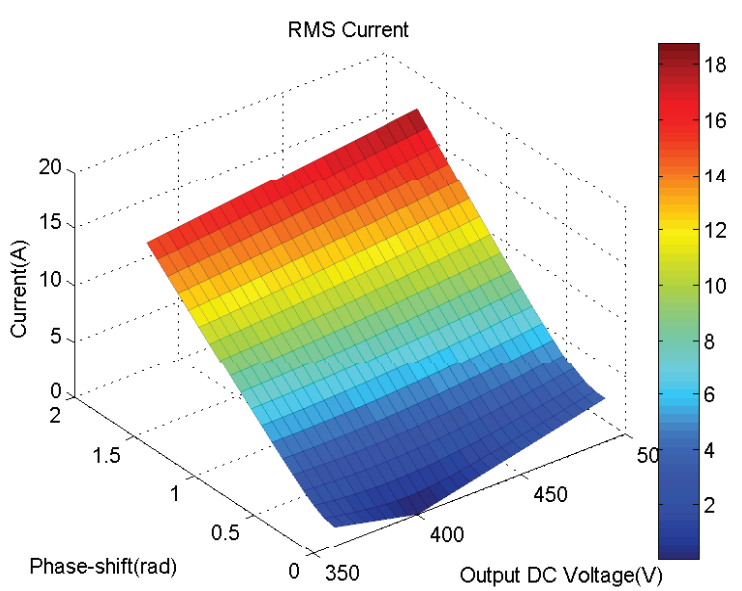

Figure 5: RMS Current vs. phase-shift and output voltage.

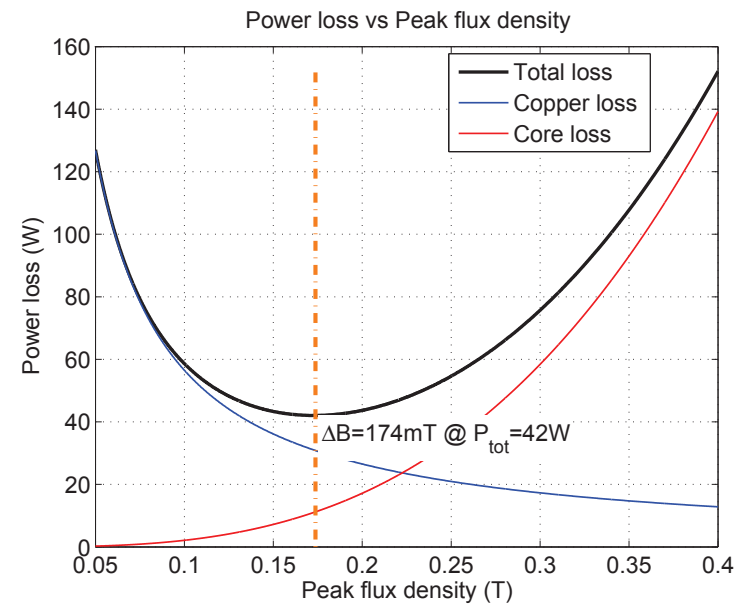

Figure 6: Power losses as function of peak flux density. 
Table III: Transformer design output data

\begin{tabular}{|c|c|c|}
\hline \multicolumn{2}{|l|}{ Core } & $2 \times \mathrm{T} 102 / 66 / 25,3 \mathrm{C} 90$ from Ferroxcube ${ }^{\circledR}$ \\
\hline \multicolumn{2}{|l|}{ Windings } & 44 turns of $5 \times$ AWG21, twisted \\
\hline \multicolumn{2}{|l|}{ Core losses } & $11.21 \mathrm{~W}$ \\
\hline \multicolumn{2}{|l|}{ Cooper losses } & $30.81 \mathrm{~W}$ \\
\hline \multicolumn{2}{|c|}{ Total power losses } & $42.02 \mathrm{~W}$ \\
\hline \multicolumn{2}{|c|}{ Peak induction } & $173.7 \mathrm{mT}$ \\
\hline \multicolumn{2}{|l|}{ Current density } & $7.45 \mathrm{~A} / \mathrm{mm}^{2}$ \\
\hline \multirow{2}{*}{$\begin{array}{l}\text { Magnetization } \\
\text { inductance }\end{array}$} & Calculated & $11.71 \mathrm{mH}$ \\
\hline & Measured & $12.41 \mathrm{mH}$ (TEGAM 252, 1mA, 1kHz) \\
\hline \multirow[t]{2}{*}{ DC Resistance } & Calculated & $0.0439 \Omega\left(20^{\circ} \mathrm{C}\right)$ \\
\hline & Measured & $0.0404 \Omega$ (Fluke $79,5 \mathrm{~A} \mathrm{DC}, 16^{\circ} \mathrm{C}$ ) \\
\hline \multicolumn{2}{|c|}{ Leakage inductance } & $<3.8 \mu \mathrm{H}($ TEGAM $252,100 \mathrm{~mA}, 1 \mathrm{kHz})$ \\
\hline
\end{tabular}

\section{Control and Interface}

The control hardware designed for this application is built around a TI C2000 family digital signal controller. This controller has several internal peripherals with emphasis on the 16-channel analog acquisition module and the 8 module PWM generator with phase-shift feature. For the implementation of the control application, a computer-based graphical user interface featuring signal plotting and parameter read/write capabilities was developed with debug and monitoring purposes. The conceptual control scheme for the communication and EV Charger control is split in three modules. These modules include the EV Charger Control, CAN and serial communications. They are divided in tasks and implemented using Matlab/Simulink. This division decreases the coding time and makes it easier to reach a valid prototype.

The main task is used to control the power converter in closed loop and is triggered by the interruption generated after the ADC acquisition complete sequence. Includes the variables acquisition, grid synchronization algorithm, power flow control and generation of command signals. In the power flow control is included the battery management and the voltage and frequency droops. The storage of data used for monitoring is implemented in this task to achieve a real-time sampling.

The communication tasks are used for communication with the computer interface and the BMS. Calls are made when a new valid message is received and after the control task execution ends. A CAN port receives data regarding the batteries such as $\mathrm{SoC}$, SoH and $\mathrm{min} / \mathrm{max}$ cell voltage, which are used for the control and also sent to the user interface via a serial port. Serial communication is in charge of exchanging data between the control device and the user interface. Some more relevant data such as new droop parameters and battery SoC are exchanged between the user interface and the grid management.

The task management has been made by the Task Scheduler (TS) included in Simulink Embedded Coder for TI [21]. This way, all tasks have the execution isolated running in pseudo parallelism. The control task has the top priority of the whole architecture and is non-preemptible. The EC provides several libraries to create a Simulink model compatible with Real Time Workshop (RTW) code generation tool. The RTW for TI C2000 family translates the Simulink diagram into code ready to be compiled by the Code Composer Studio software. The objective of using this structure for the task management is to fulfill the control real time requirements, being the TS a key component. The proposed architecture was inspired by the concept round robin with interrupts $[22,23]$. The TS manages all the program execution using the eZdsp hardware interrupts.

\section{Experimental results}

\section{Converter operation}

This section presents the obtained results, which allowed to verify the operation of the electronic converter and its performance. Special importance was given to the evaluation of power quality in both sides, the mains and battery pack interfaces, and also to the converter dynamic response.

First test presents the voltages and secondary current of the transformer and the battery current when the battery bank is charging (Fig. 7). Since battery pack voltage is greater than DC bus, the DAB was running in boost mode. Both bridges are switched with a bipolar pattern and the voltages applied to the high-frequency transformer are phase-shifted square waves with $50 \%$ duty-cycle. The DAB converter is in charging mode when the primary voltage leads secondary voltage and $\phi$ is denoted as positive. In discharging mode, secondary voltage of the transformer leads primary voltage and $\phi$ is denoted as negative. It can be seen that the battery pack current has a low ripple. 


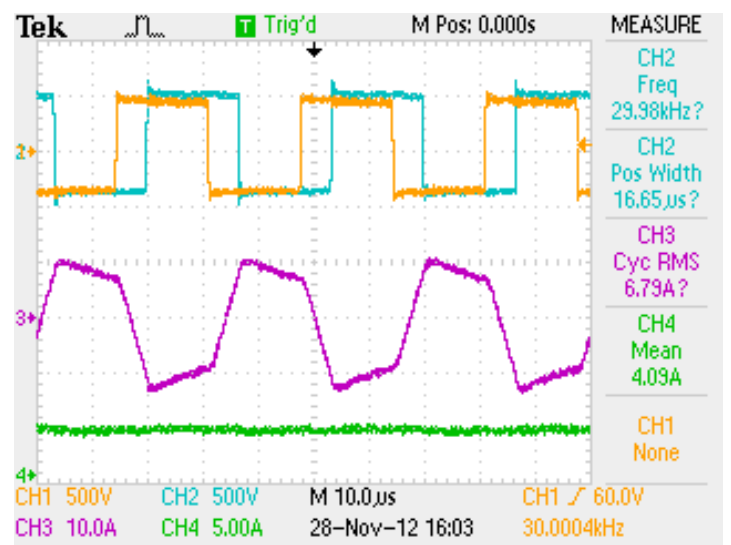

Figure 7: DAB waveforms in charging mode with $\phi=60^{\circ}$. Transformer primary side voltage $(\mathrm{CH} 1)$, secondary side voltage $(\mathrm{CH} 2)$ and current $(\mathrm{CH} 3)$, battery pack current $(\mathrm{CH} 4)$.

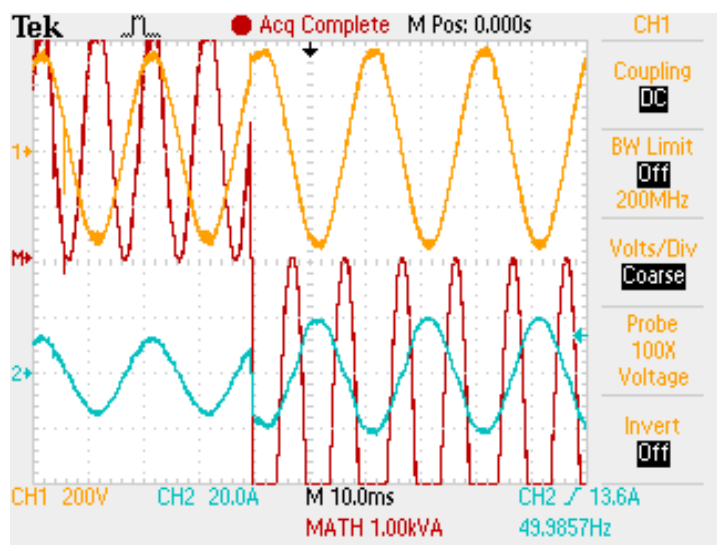

Figure 8: Voltage and current on grid interface during a power flow inversion. Grid voltage $(\mathrm{CH} 1)$, grid current $(\mathrm{CH} 2)$ and instantaneous power (MATH).

The second experiment illustrates the voltage, $v_{A C}$, and current in the grid, $i_{s}$, during an instant power flow inversion and it is used to evaluate the dynamic response of the converter (Fig. 8). As it can be seen, the converter can rapidly change between charge and discharge modes without significant disturbance on the grid voltage waveform. It should be noted that the grid synchronization algorithm is operating as expected, both in charge and discharge modes. It must also be emphasized that the power factor is maintained almost unitary in both modes of operation and a low harmonic content is generated.

\section{Voltage Droop}

To verify the performance of the proposed droop control and demonstrate the impact on the voltage regulation, an experimental setup was configured based on the resources available at the INESC Porto Smart Grids with Electric Vehicles Laboratory (SGEVL). The test circuit comprises a MV/LV distribution transformer, a resistive cable simulator and a remote node. The consumer/producer of electricity is represented by the remote node and contains the prototype under test, a solar inverter and a variable resistive load. For the test, two modes of operation - with and without droop control - were considered. The solar inverter supplies a fixed $3 \mathrm{~kW}$ power during the whole test. Resistive load is sequentially increased from zero to $8,1 \mathrm{~kW}$, corresponding to the different load steps. Voltage droop parameters were set according to the characteristics of the used node and are shown in Fig. 10. A test divided into five equal intervals of 9 second each was performed to evaluate the impact of droop control in the node voltage (Fig. 9). The goal for the node voltage was to achieve a variation not exceeding $\pm 10 \%$ in any of the scenarios when droop control is used, complying with EN-50160 standard.

Without the droop control, it can be seen that the voltage drops to as low as 197V in heavy load condition and, on the other hand it can rise to $248 \mathrm{~V}$ when there is microgeneration and no load. Using droop based voltage regulation, it is possible to maintain the value in a range of $\pm 10 \%$ being always far from the upper and lower limits defined, respectively $207 \mathrm{~V}$ and $253 \mathrm{~V}$. For the first interval, it is intended for the node to be operating with a typical load. Afterwards, the resistive load is turned off and the voltage
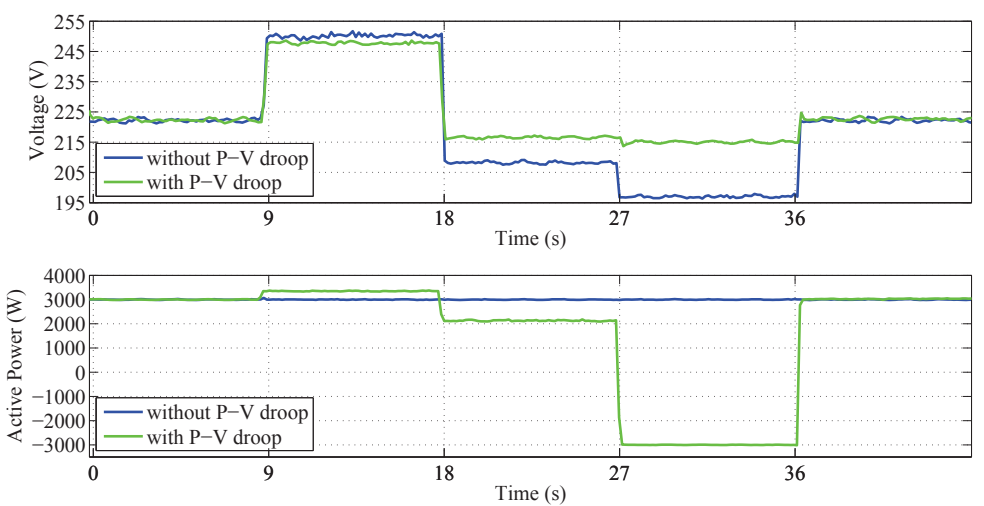

Figure 9: Node voltage and charger power vs. time in both operation modes.

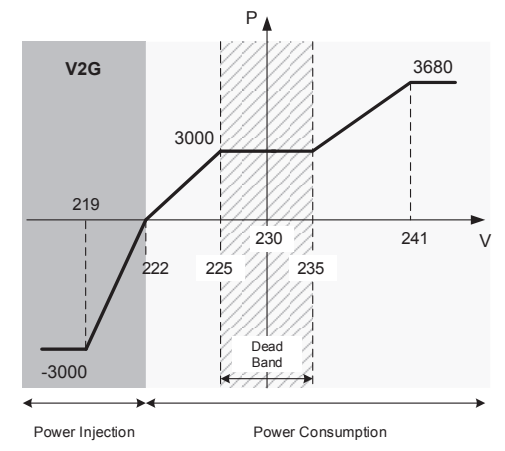

Figure 10: Voltage droop parameters. 
rises, and the prototype slightly increases the power consumption to prevent a voltage swell. In the third interval a high load is connected, decreasing the node voltage, which is compensated by a decrease in the prototype power consumption. A very heavy load is connected in the fourth interval and it is possible to verify that the prototype has the ability to reverse the power flow, preventing the occurrence of a voltage dip.

\section{Frequency Droop}

For the frequency droop demonstration, an island microgrid experimental setup was configured. A threephase system with nominal power of $15 \mathrm{~kW}$ is implemented in the laboratory using three Sunny Island grid forming inverters, with $50 \mathrm{kWh}$ energy storage capacity. The node is powered by standalone inverters and has been connected to the prototype under test and to a variable resistive load. These inverters are characterized by rising node frequency when there is an excess of power production and the storage unit is fully charged. On the other hand, the fall in frequency can be observed when a transition between gridtied and island mode takes place. Frequency droop parameters were set according to the characteristics of the configured node and are shown in Fig. 12.

To test the droop response, the two previously described situations were provoked. The dynamic response of the prototype was captured using a Fluke ${ }^{\circledR}$ 1760TR high end power analyzer (Fig. 11). The aim is that the prototype rapidly sinks or sources a large amount of energy, so that transient variations are reduced in duration and magnitude. In the first transient captured, it can be observed that the frequency drops to $49.2 \mathrm{~Hz}$ and the prototype power flow is promptly reversed to aid the frequency regulation of the grid forming inverters. The second experiment illustrates the frequency rise originated by the excessive power generation and reach of battery capacity limit. This situation is compensated with an increase in power consumption by the prototype. When frequency reaches $50.2 \mathrm{~Hz}$ the generation is lost and the value goes back to $50.0 \mathrm{~Hz}$.
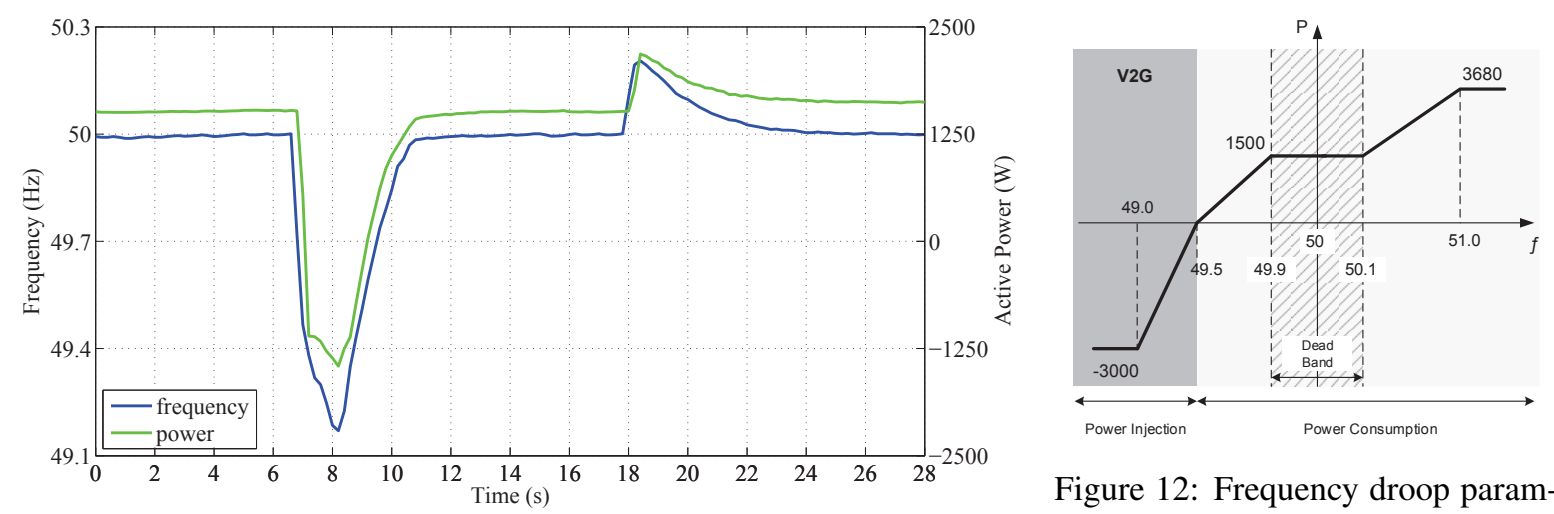

Figure 12: Frequency droop param-

Figure 11: Node frequency and charger power vs. time during transients. eters.

\section{Conclusion}

A bidirectional and isolated battery charger design and implementation have been presented. The control system implemented was found to be quite suitable for this application, allowing a fast and accurate set-point tracking. The method used for the transformer design was considered interesting, resulting in a reasonable performance component with a reduced design effort. The impact of the droop regulation method implemented in this prototype demonstrates clear advantages when compared to a conventional battery charger, allowing a better power balance in low-voltage microgrids by changing the EV charging rates according to local grid conditions (in terms of voltage and frequency).

A realistic test layout implemented in the laboratory representing a residential customer with single phase connection was used to show that critical node voltage levels can easily be avoided with a bidirectional droop-controlled battery charger. During the test was proved that voltage levels are within the limits of the EN-50160 standard. The response to frequency variations was tested in off-grid mode, with the prototype showing the ability to contribute to the frequency stabilization when there are transitions between interconnected and islanded mode, and also to increase their consumption when there is excessive microgeneration.

Droop profiles must be configured according to the characteristics of each node to ensure that there is no permanent increase or decrease in the charging rate during normal grid operation. The slopes should also be defined to ensure an appropriate response for each situation. These results show that advanced features can be added to the battery chargers, making them devices that can be integrated in low voltage grid and, more than that, contributing actively to ensure high power quality and management features in microgrids. 


\section{References}

[1] A. Y. Saber and G. K. Venayagamoorthy, "One million plug-in electric vehicles on the road by 2015," in Intelligent Transportation Systems, 2009. ITSC '09. 12th International IEEE Conference on, 2009, pp. 1-7.

[2] Y. Chen, A. Oudalov, and J. S. Wang, "Integration of electric vehicle charging system into distribution network," in Power Electronics and ECCE Asia (ICPE \& ECCE), 2011 IEEE 8th International Conference on, 2011, pp. 593-598.

[3] J. A. P. Lopes, F. J. Soares, and P. M. R. Almeida, "Integration of Electric Vehicles in the Electric Power System," Proceedings of the IEEE, vol. 99, pp. 168-183, 2011.

[4] J. D. Kueck, A. F. Snyder, L. Fangxing, and I. B. Snyder, "Use of Responsive Load to Supply Ancillary Services in the Smart Grid: Challenges and Approach," in Smart Grid Communications (SmartGridComm), 2010 First IEEE International Conference on, 2010, pp. 507-512.

[5] I. Cvetkovic, T. Thacker, D. Dong, G. Francis, V. Podosinov, D. Boroyevich, et al., "Future home uninterruptible renewable energy system with vehicle-to-grid technology," in Energy Conversion Congress and Exposition, 2009. ECCE 2009. IEEE, 2009, pp. 2675-2681.

[6] R. J. Rei, F. J. Soares, P. M. R. Almeida, and J. A. Pecas Lopes, "Grid interactive charging control for plug-in electric vehicles," in Intelligent Transportation Systems (ITSC), 2010 13th International IEEE Conference on, 2010, pp. 386-391.

[7] D. C. Erb, O. C. Onar, and A. Khaligh, "Bi-directional charging topologies for plug-in hybrid electric vehicles," in Applied Power Electronics Conference and Exposition (APEC), 2010 Twenty-Fifth Annual IEEE, 2010, pp. 2066-2072.

[8] M. Yilmaz and P. T. Krein, "Review of Battery Charger Topologies, Charging Power Levels, and Infrastructure for Plug-In Electric and Hybrid Vehicles," Power Electronics, IEEE Transactions on, vol. 28, pp. 2151-2169, 2013.

[9] R. J. Ferreira, L. M. Miranda, R. E. Araujo, and J. P. Lopes, "A new bi-directional charger for vehicle-togrid integration," in Innovative Smart Grid Technologies (ISGT Europe), 2011 2nd IEEE PES International Conference and Exhibition on, 2011, pp. 1-5.

[10] M. N. Kheraluwala, R. W. Gascoigne, D. M. Divan, and E. D. Baumann, "Performance characterization of a high-power dual active bridge," Industry Applications, IEEE Transactions on, vol. 28, pp. 1294-1301, 1992.

[11] F. Krismer and J. W. Kolar, "Efficiency-Optimized High-Current Dual Active Bridge Converter for Automotive Applications," Industrial Electronics, IEEE Transactions on, vol. 59, pp. 2745-2760, 2012.

[12] J. Everts, J. Van den Keybus, F. Krismer, J. Driesen, and J. W. Kolar, "Switching control strategy for full ZVS soft-switching operation of a Dual Active Bridge AC/DC converter," in Applied Power Electronics Conference and Exposition (APEC), 2012 Twenty-Seventh Annual IEEE, 2012, pp. 1048-1055.

[13] M. Ciobotaru, R. Teodorescu, and F. Blaabjerg, "A New Single-Phase PLL Structure Based on Second Order Generalized Integrator," in Power Electronics Specialists Conference, 2006. PESC '06. 37th IEEE, 2006, pp. $1-6$.

[14] R. J. Ferreira, R. E. Araujo, and J. A. Pecas Lopes, "A comparative analysis and implementation of various PLL techniques applied to single-phase grids," in Energetics (IYCE), Proceedings of the 2011 3rd International Youth Conference on, 2011, pp. 1-8.

[15] L. Ray-Shyang and K. D. T. Ngo, "A PWM method for reduction of switching loss in a full-bridge inverter," Power Electronics, IEEE Transactions on, vol. 10, pp. 326-332, 1995.

[16] Extend Concepts of MG by Identifying Several EV Smart Control Approaches to be embedded in the Smart Grid Concept to manage EV individually or in Clusters, Deliverable 1.2. Available: http://www.evmerge.eu/images/stories/uploads/MERGE_WP1_D1.2_Final.pdf

[17] J. A. Pecas Lopes, P. M. Rocha Almeida, and F. J. Soares, "Using vehicle-to-grid to maximize the integration of intermittent renewable energy resources in islanded electric grids," in Clean Electrical Power, 2009 International Conference on, 2009, pp. 290-295.

[18] J. Tomić and W. Kempton, "Using fleets of electric-drive vehicles for grid support," Journal of Power Sources, vol. 168, pp. 459-468, 2007.

[19] Rahimi-Eichi, H.; Ojha, U.; Baronti, F.; Chow, M., "Battery Management System: An Overview of Its Application in the Smart Grid and Electric Vehicles," Industrial Electronics Magazine, IEEE , vol.7, no.2, pp.4,16, June 2013

[20] R. W. Erickson and D. Maksimovic, Fundamentals of Power Electronics, 2nd ed.: Springer, 2001, Chap. 15.

[21] I. The MathWorks. (2013, 15 January). Code Generation - Embedded Coder - Simulink. Available: http://www.mathworks.com/products/embedded-coder/

[22] D. Hristu-Varsakelis and W. S. Levine, Handbook of Networked and Embedded Control Systems: Birkhäuser Boston, 2005.

[23] R. Zurawski, Embedded systems: handbook: CRC/Taylor \& Francis, 2006. 